\title{
Primary Renal Lymphoma - A Challenging Diagnosis
}

Kanwal Ali, M. Anis Ul Islam, Fahad Mushtaque, Hussain Ahmad, Haroon Sabir Khan, Mahwish Mahboob Bhutta

- - - - - - - - - - - - - - - - - - - - - - - - - - ABSTRACT:

Primary renal lymphoma is rare challenging diagnostic dilemma. Many cases have been found in literature, but a clear diagnostic criterion is still evolving. Chemotherapy is the treatment of choice, however due to its rarity; it is often misdiagnosed, which leads to nephrectomies resulting in unnecessary morbidity. A case of a 60 years old male found to have a renal mass, being treated as renal cell carcinoma. Exploration for radical nephrectomy resulted in an open biopsy instead due to a fixed, hard, inoperable renal mass. Diagnosis of lymphoma was made by histological confirmation of the disease and patient was treated with chemotherapy.

KEY WORDS: Lymphoma, Mass, Primary, Renal How to cite this Article:
Ali K, UlIslam A, Mushyaque F, Ahmad H, Khan HS, Bhutta MM. Primary Renal Lymphoma - A Challenging Diagnosis J Bahria Uni
Med Dental Coll. 2021; 11(4):184-186 DOI: https://doi.org/10.51985/JBUMDC2021043
This is an Open Access article distributed under the terms of the Creative Commons Attribution Non Commercial License (http:// creativecommons/org/licences/by-nc/4.0)
which permits unrestricted non commercial use, distribution and reproduction in any medium, provided the original work is properly cited.

- - - - - - - - - - - - - - - - - - - - - - - - - - - - - -

\section{INTRODUCTION:}

Primary renal lymphoma is a rare entity and is often overlooked when diagnosing renal mass. It represents less than $1 \%$ of all renal lesions of which diffuse large B cell lymphoma is the more common pathological variant. ${ }^{1-3}$ Renal parenchyma is devoid of lymphoid tissue; hence, it has been suggested that the lymphoma may originate from lymphatics in the renal capsule, which then invades the renal parenchyma. ${ }^{4,5}$ Its prognosis is usually poor and surgical treatment is rarely feasible. ${ }^{6}$ However, early diagnosis and prompt treatment with chemotherapy may improve the prognosis of the patient. Thus although rare, it is very important to distinguish between renal cell carcinoma and primary renal lymphoma during workup of renal mass.

\section{CASE REPORT:}

A 60 years old male presented with pain in the left lumbar

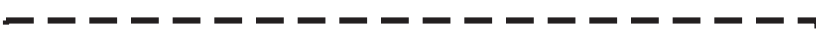

I KANWAL ALI

Resident, Department of Urology

Bahria University Medical and Dental College, Karachi

I Email: kanwal2307@gmail.com

I M. ANIS UL ISLAM

I Assistant Professor, Department of Urology

I Bahria University Medical and Dental College, Karachi

I FAHAD MUSHTAQUE

Resident, Department of Urology

Bahria University Medical and Dental College, Karachi

HUSSAIN AHMAD

Professor, Department of Urology

I Bahria University Medical and Dental College, Karachi

I HAROON SABIR KHAN

I Professor, Department of Urology

I Bahria University Medical and Dental College, Karachi

I MAHWISH MAHBOOB BHUTTA

Resident, Department of Surgery

I Bahria University Medical and Dental College, Karachi

Received: 07-Jul-2021

Accepted: 07-Sep-2021 region for the past 3 months. His pain was mild in intensity, dull and gradual in onset. He also had an episode of painless hematuria.

Clinical examination revealed a diffuse, non-tender, firm mass in the left flank and there was no cervical or other lymphadenopathy or hepatosplenomegaly. Complete blood picture, coagulation profile, diabetic profile, liver function tests and renal function tests, were within normal parameters. Urinalysis was unremarkable. The Ultrasonogram of left kidney showed a rounded isoechoic mass measuring 7.7x7.0 $\mathrm{cm}$ filling most of the medullary area of the pelvis and showing vascularity on color Doppler. It also revealed a large cystic area measuring $5.9 \times 4.7 \mathrm{~cm}$ with calcific foci at the superior pole of right kidney. Contrast Enhanced Computed Tomography of kidney ureters and bladder displayed a heterogeneous hypodense lesion measuring $7.2 \times 6.9 \mathrm{~cm}$ with ragged margins showing mild enhancement and occupying the whole renal pelvis and proximal ureter on left side. Loss of interface was also noted with infiltration of left psoas muscle posterior-inferiorly and Gerota's fascia anteriorly with perinephric fat strandings (Fig 1\&2). However, there was no renal vein involvement noted. Few para-aortic lymph nodes were also noted. The largest one was anterior to the crura on left side measuring $1.8 \times 0.9 \mathrm{~cm}$, another below renal vein measuring $1 \times 0.4 \mathrm{~cm}$ and another one along

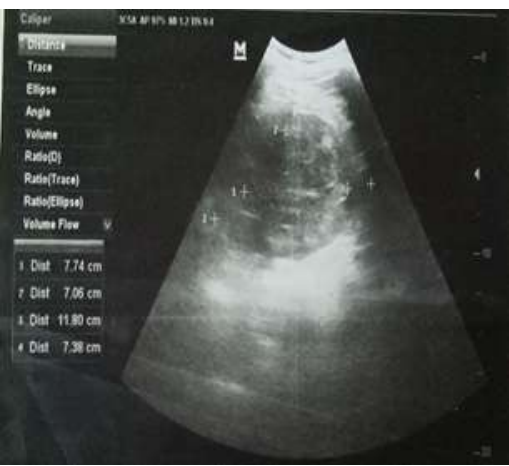

Fig 1. The ultasonogram of left kidney showing isoechoic mass filling the medullary area 
celiac axis measuring 9x0.6 cm. Contrast Enhanced Computed Tomography of chest was normal. The radiological features were favoring renal cell carcinoma Stage IIa so radical nephrectomy was attempted

On exploration, the tumor was nodular and hard with extensive desmo-reaction around tumor area abutting pancreas and jejunum. Descending colon was also densely adherent to anterior surface of the tumor extending to splenic and pancreatic region. Posteriorly the tumor was fixed to the wall. Hilar region was immobile and renal vein and artery could not be identified. The operative findings concluded that the tumor was irresectable, so open biopsy was taken before closing the wound. The histopathology of specimen revealed sheets of intermediate to large round to oval cells having vesicular nuclei with clear cytoplasm (Fig 3). Immunochemical stains were positive for LCA, CD 3
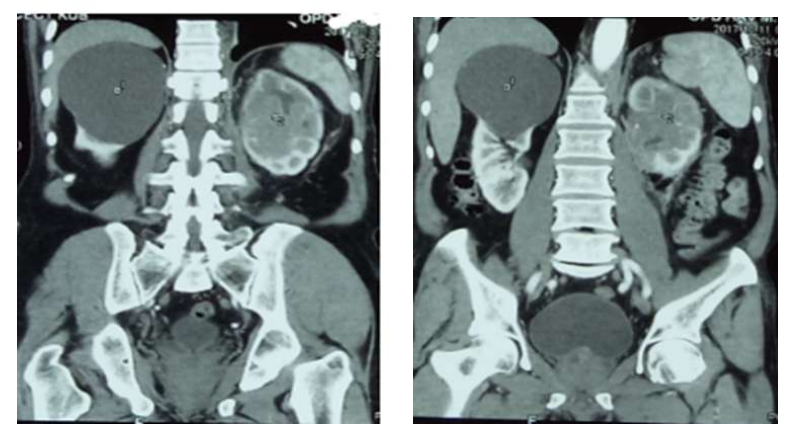

Figure 1: Lesion occupying the renal pelvis and upper ureter in left kidney

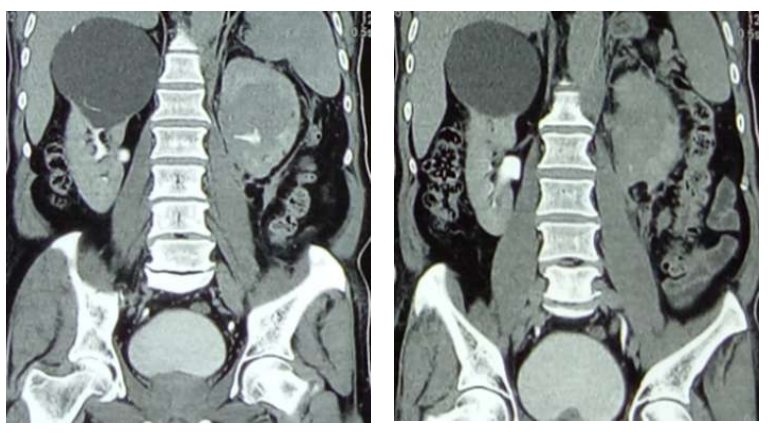

Figure 2: Lesion appearing hypodense on contrast enhancement

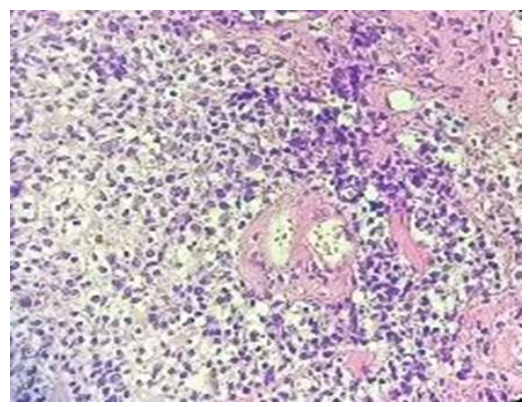

Figure 3: Intermediate to large round to oval cells with vesicular nuclei and clear cytoplasm and $\mathrm{Ki} 67$, suggesting that the mass is non-Hodgkin lymphoma diffuse large B cell type. His bone marrow aspiration from posterior iliac spine showed reactive changes. The patient was started on chemotherapy cycles with vincristine, doxorubicin, cyclophosphamide, dexamethasone, and prednisolone. He showed complete regression of lymphoma with disappearance of the tumor. He was on monthly follow-up for 9 months followed by 6 monthly follow-up for 2 year with no remission of lymphoma, which confirmed it to be primary renal lymphoma.

\section{DISCUSSION:}

Primary extra-nodal Non-Hodgkin lymphoma accounts for one-third of all non-Hodgkin lymphoma ${ }^{3}$. Primary renal lymphoma is defined as non-Hodgkin lymphoma originating from renal parenchyma in the absence of extra renal lymphatic disease. In 1980, Coggins reported the first confirmed case of primary renal lymphoma ${ }^{7}$. It is an uncommon entity that accounts for only $0.1 \%$ of all malignant lymphomas and $0.7 \%$ of all extra-nodal non-Hodgkin lymphomas ${ }^{8}$. However, secondary renal involvement in cases of non-Hodgkin lymphoma is very common and usually occurs in disseminated cases ${ }^{9}$.

Renal parenchyma is devoid of lymphatic tissue hence the origin of primary renal lymphoma has been considered uncertain. There are several pathogenic mechanisms proposed about its origin including the lymphatic vessels of renal capsule or sub capsular tissue that progresses to penetrate renal parenchyma and extension of an inflammatory disease with lymphoplasmacytic infiltrates that then endures oncogenic transformation. ${ }^{5,7,10,11}$ However, the later phenomenon is not well known in other case reports including our own case.

Primary renal Lymphoma is an infiltrative tumor that attacks without disrupting the architecture or function of the kidney. It usually affects adults. The most common presenting symptoms include flank pain and mass ${ }^{7}$. Acute kidney failure is also a common clinical exhibition documented in literature.

According to Stallone et al, the criteria for diagnosing primary renal lymphoma includes lymphomatous renal dissemination, non-obstructive unilateral or bilateral renal expansion and no extra renal involvement of the disease at the time of diagnosis. ${ }^{2}$ Some studies emphasize on the absence of lymph node involvement for primary renal lymphoma, whereas in others, coexisting para-aortic lymph node involvement may be present along with a renal lesion, which was present in our case. ${ }^{4}$

Imaging plays a vital role in diagnosing primary renal lymphomas. On ultrasonography, it may appear as hypo to isoechoic mass with decreased vascularity. The most common encountered Computed Tomography patterns include multiple renal masses, renal invasion from adjoining retro peritoneal disease, perirenal or diffuse renal infiltration in the absence of hydro nephrosis and solitary lesion. ${ }^{12}$ It is very challenging 
to distinguish radiologically between primary renal lymphomas and renal cell carcinomas especially in cases of unilateral masses. On computed tomography, post contrast hypodense or non-enhancing lesion points more towards primal renal lymphoma whereas existence of renal vein thrombus and calcification, pressure effect on pelvicalyceal system and renal vessels, hyper vascularity and invasion of inferior vena cava hints towards renal cell carcinoma. ${ }^{3} \mathrm{On}$ magnetic resonance imaging, lower signal strength on unenhanced T1-weighted images than normal renal cortex and less enrichment on early gadolinium-enhanced images are more suggestive of primary renal lymphoma. ${ }^{11,13}$

Renal biopsy has revealed a sensitivity of $70 \%$ to $92 \%$ and specificity of nearly $100 \%$ in the diagnosis of primary renal lymphoma. ${ }^{14}$ Diffuse large B cell type is the most frequent histological variant of primary renal lymphomas. ${ }^{3}$ However, other histological types such as follicular lymphoma, MALToma or small lymphocytic lymphoma have also been reported.

It is vital to distinguish primary renal lymphoma from other masses because of the disparity in their treatment. Treatment of choice in renal malignancies is usually radical nephrectomy, on the contrary, primary renal lymphoma responds well to systemic chemotherapy using CHOP (Cyclophosphamide, Adriamycin, Vincristine and Prednisone) regime. ${ }^{15}$ Recent studies have also shown that adding rituximab to the classical CHOP (Cyclophosphamide, Adriamycin, Vincristine and Prednisone) chemotherapy improves outcomes. ${ }^{7,16,17}$ The prognosis of primary renal lymphoma is promising only if early diagnosis and prompt chemotherapy is started.

\section{CONCLUSION:}

Although primary renal lymphoma is an uncommon disease, it should always be kept in mind when exploring a renal mass. A thorough workup should be carried out and biopsy is mandatory if radiological features are suggestive, to confirm the diagnosis as it will avoid unnecessary nephrectomy.

Гuthors Contribution:

I Kanwal Ali: Substantial, design, writeup

M. Anis UI Islam: Analysis

Fahad Mushtaque: Analysis

I Hussain Ahmad: Contribution of concept

Haroon Sabir Khan: Analysis design, contribution of concept I

Mahwish Mahboob Bhutta: Data analysis

L _ - - - - - - - - - - - - -

\section{REFERENCES}

1. Witzig TE. Primary Renal Non- Hodgkin's Lymphoma An Unusual Extranodal Site. Cancer. 1995;75(9):2258-61.

2. Stallone G, Infante B, Manno C, Campobasso N, Pannarale G, Schena FP. Primary renal lymphoma does exist: Case report and review of the literature. J Nephrol. 2000;13(5):367-72.
3. Cheng X, Huang Z, Li D, Wang Y. Enormous primary renal diffuse large B-cell lymphoma: A case report and literature review. J Int Med Res. 2019;47(6):2728-39.

4. Yasunaga Y, Hoshida Y, Hashimoto M, Miki T, Okuyama A, Aozasa K. Malignant lymphoma of the kidney. J Surg Oncol. 1997;64(3):207-11.

5. Rissman CM, Dagrosa LM, Pettus JR, Dillon JL, Sverrisson EF. Primary renal lymphoma: an unusual finding following radical nephrectomy. Clin Nephrol - Case Stud. 2017;5:1-4.

6. Naveen Kumar BJ, Barman P, Chowdhury N BM. Primary renal lymphoma: An unusual presentation of non-Hodgkin's lymphoma. Indian J Cancer. 2014;51(3):369-70.

7. Bokhari SRA, Inayat F, Bokhari MR, Mansoor A. Primary renal lymphoma: A comprehensive review of the pathophysiology, clinical presentation, imaging features, management and prognosis. BMJ Case Rep. 2020;13(6).

8. Hagihara M, Hua J, Iwaki Y, Inoue M, Sato T. Primary renal lymphoma: A case report and literature review. Intern Med. 2015;54(20):2655-9.

9. Geetha N, Shahid A, Rajan V, Jacob PM. Primary renal lymphoma - a case report. Ecancermedicalscience. 2014;8:2-6.

10. Omer HA, Hussein MR. Primary renal lymphoma. Nephrology. 2007;12(3):314-5.

11. Cyriac S, Rejiv R, Shirley S, Sagar GT. Primary renal lymphoma mimicking renal cell carcinoma. Indian J Urol. $2010 \mathrm{Jul} ; 26(3): 441-3$.

12. El-Sharkawy MS, Siddiqui N, Aleem A, Al Diab A. Renal involvement in lymphoma: Prevalence and various patterns of involvement on abdominal CT. Int Urol Nephrol. 2007;39(3):929-33.

13. O'Riordan E, Reeve R, Houghton JB, O'Donoghue DJ, Waldek S. Primary bilateral T-cell renal lymphoma presenting with sudden loss of renal function. Nephrol Dial Transplant. 2001;16(7):1487-9.

14. Chenal M, Molina H, Mendez V, Poole J, Parellada C. Uncommon presentations of non-Hodgkin's lymphoma. J Clin Oncol. 2003;21(3):567-9.

15. Shetty S, Singh AC, Babu V. Primary Renal Lymphoma - A Case Report and Review of Literature. J Clin Diagnostic Res. 2016;10(9):9-11.

16. Alonso FV, Ramos CS, Prados FJV, Geler MP, Carozo ER, Massare PB, et al. Linfoma renal primario: aportación de tres nuevos casos y revisión de la literatura. Vol. 62, oncology urology. Arch Esp Urol; 2009.p.461-5.

17. Taneja A, Kumar V, Chandra AB. Primary renal lymphoma: A population-based analysis using the SEER program (19732015). Eur J Haematol. 2020;104(5):390-9.

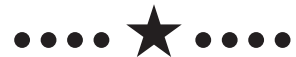

